The virtual elimination of juvenile goitre which has been witnessed in Tasmania over the past decade $^{1}$ has been attributed to the deliberate addition of iodate to bread improver and thus to all commercially baked bread. Subsequently it has become apparent that the increased iodine content of milk derived from the use of iodophors in the dairy industry also contributed to improved iodine nutrition. Recent surveys conducted by the Department of Public Health show that: (1) bread consumption by schoolchildren is falling, (2) a proliferation in available bread improvers makes it impossible to guarantee the iodine content of bread, and (3) a substantial proportion of schoolchildren are now dependent on the iodine they derive from milk to maintain iodine sufficiency. Should iodophors be withdrawn and the iodine content of milk revert to low levels many children would again be iodine-deficient.

No doubt in other areas of iodine deficiency the contamination of milk with iodine from iodophor residues has led to relief of the deficiency and the price has already been paid in an increase of thyrotoxicosis in the middleaged and elderly. To ban iodophors in these circumstances would rob the young of the benefits for which their elders have already paid. A detailed study by Dunsmore and Wheeler $^{2}$ has shown that with correct usage iodophors need add no more than $1.2 \mu \mathrm{mol} / \mathrm{l}$ $(15 \mu \mathrm{g} / 100 \mathrm{ml})$ to the iodine content of milk. Iodine at this level is not excessive and milk is a suitable vehicle for goitre prophylaxis as its consumption tends to be higher in the young than the old.

Our plea is that iodine contamination of food should be controlled but not necessarily banned and that action should be taken only after a full appraisal of the local circumstances in relation to goitre incidence and iodine nutrition.

J C STEWART G I VIDOR

Thyroid Clinic,

Launceston General Hospital,

Launceston, Tasmania

' Tasmanian Thyroid Advisory Committee, unpublished

data.
Dunsmore, D S, and Wheeler, A M, Australian fournal of Dairy Technology. In press.

\section{Chronic urticaria}

SIR,-As a comment on your leading article on this subject ( 10 July, p 68) we should like to report results obtained in our urticaria clinic set up nine months ago.

Of 72 patients, 37 had chronic urticaria (that is, urticaria occurring for two months or longer) and were in an active phase at the time of attendance. Most had been treated with two or more antihistamines unsuccessfully before referral. All were routinely investigated, as a result of which three patients were found to have antistreptolysin 0 titres of $>300$ units $\mathrm{ml}$ and $\beta$-haemolytic streptococci were grown from throat swabs from two further patients. Two patients were found to be thyrotoxic and one man, who had had a previous nephrectomy, had a urinary infection. Three patients had signs of old and persistent sinus infection.

Each patient also had an intradermal Candida albicans prick test (Bencard) and was given a series of identical capsules containing tartrazine, sodium benzoate, 4-hydroxybenzoic acid, yeast extract, penicillin, and aspirin
$100 \mathrm{mg}$ and $600 \mathrm{mg}$ interspersed with control capsules as described by Warin and Smith. ${ }^{1}$ This was done at a time when the urticaria was partially but not totally controlled by an oral antihistamine. Only one patient had a weakly positive type I response to the $C$ albicans skin test and only two patients had reproducibly positive reactions to the oral provocation capsules. A third patient had a strongly positive reaction after the administration of aspirin $100 \mathrm{mg}$ and it was felt unsafe to repeat the test. A fourth patient reacted strongly to tartrazine administration; owing to the activity of his urticaria rechallenging was not possible, but a low-tartrazine diet produced an excellent response. Of the two patients with reproducible reactions, one, who reacted to sodium benzoate administration, cleared completely on a lowbenzoate diet. The other reacted to penicillin and her urticaria cleared on a diet low in milk products. All patients were advised to avoid aspirin. ${ }^{2}$

The administration of the rather large capsules has not proved a problem. We advise that they be taken with a hot drink on waking Nearly all the patients developed urticaria after administration of the first capsule (a control) and many of them had weals throughout the test period.

Although it is too early to draw definite conclusions from this study we have not been able to confirm previous work using test capsules which showed positive reactions in 66 out of 111 patients. ${ }^{1}$ In particular, with the dosages of aspirin employed we have seen an exacerbation of urticaria on only one occasion and this is a man already known to be aspirin-sensitive. As yet we cannot know whether the improvement in the three patients treated by diet is due to the diets alone. If it is, does it justify the lengthy screening procedure involved or is there an easier way to locate the offending substance?

The lack of reactions to $C$ albicans intradermal prick testing is also at variance with James and Warin's work." They reported that $11^{\circ}$ of patients with chronic urticaria had positive prick tests (type I response) with $C$ albicans out of a total of $36^{\circ}$ o positive reactors.

We are surprised at our very differen findings from the previous series and would be interested to hear of other workers' experience.

A E SOLOMON J MaCAULAY

Departments of Dermatology and Pharmacy, Gow Infirmary, Glasgow

' Warin, R P, and Smith, R J, British fournal of Dermatology, 1976, 94, 401.
Moore-Robinson, M, and Warin, R P, British Medical fournal, $1967,4,62$ James, J, and Warin, R P, British fournal of Der-
matology, 1971, 83, 227.

\section{Hypoglycaemia in children undergoing} operations

SIR,-May I congratulate Drs Stephen Ware and J P Osborne (28 August, p 499) for highlighting the potentially lethal but avoidable complication of hypoglycaemia in children undergoing surgery. This is an established problem in babies and infants with cyanotic heart disease with concomitant heart failure and incipient respiratory failure whose glycogen reserves are chronically depleted. Their problems are exacerbated by feeding difficulties and this fact may be a most pressing indication for palliative surgery-for example, a Blalock shunt.

A method for preventing hypoglycaemia in these small patients has been used in this hospital for the past two years. The infant receives his last feed either by mouth or via a nasogastric tube three hours before the estimated time for induction of anaesthesia. During surgery the child receives intravenous fluids as Hartmann's solution $5-7 \mathrm{ml} / \mathrm{kg}$ body weight per hour, plus $0.2 \mathrm{~g}$ glucose $\mathrm{kg}$ body weight per hour as a $50^{\circ} \%$ solution by continuous infusion. This regimen is continued in the postoperative period, $50 \%$ glucose solution being given as a quarter of the infant's calculated total hourly fluid requirement, again by continuous infusion. Both during and after surgery the hypertonic fluid is administered through a centrally placed venous catheter inserted percutaneously via the right internal jugular vein.

Blood glucose estimations are performed two-hourly until oral or nasogastric feeding with milk has been re-established and further $50 \%$ glucose is administered if the blood glucose level is below $8 \mathrm{mmol} / \mathrm{l}(144 \mathrm{mg} / 100$ $\mathrm{ml}$ ).

Since the institution of this regimen there has been no mortality or obvious morbidity in this group of patients attributable to hypoglycaemia.

\section{Department of Anaesthetics,}

National Heart Hospital,

London W1

\section{BMA and HCSA}

SIR,-We are sure we are only a few of the many inside and outside the medical profession who never cease to be amazed at the ease with which divisions of opinion are generated and sustained among medical personnel in the hospital service, between seniors and juniors, between whole-timers and parttimers, between BMA and Hospital Consultants and Specialists Association, and so on ad nauseam.

We would have hoped, in vain it seems, that it would by now have become apparent to the profession that the possibility of resolving any given conflict of interests to the satisfaction of all of us is a myth. We would further have hoped that it would by now have come to be recognised that the exercise of consultation with all concerned on every occasion and at every turn, while basically commendable, has become a disease of the era which, carried to the extreme, becomes a lunatic performance which terminally will ensure that no satisfactory conclusion or outcome can possibly be reached.

Surely we have now arrived at the point where the consultative process must be followed by a straightforward, uncomplicated unqualified support of our negotiators, briefed to pursue the policies acceptable to the majority so that they may proceed secure in the knowledge that we will do all they require of us to ensure that the Government will not be able to retain the entrenched position it has in relation to consultant medical staff up to the present time.

Finally, please let us say to the BMA and the HCSA, the bickering must cease. We expect you to speak with one voice to secure conditions of service and remuneration which will restore morale among us, without which restoration there can be little hope of the 